\title{
INVESTIGACIONES
}

\section{¿Por qué elegir una escuela privada subvencionada? Sectores medios emergentes y elección de escuela en un sistema de mercado*}

\author{
Why to choose a semi-private school? Middle social class sectors \\ and school choice in a market system
}

\section{Manuel Canales, ${ }^{a}$ Cristián Bellei, ${ }^{b}$ Víctor Orellana ${ }^{c}$}

\author{
a Departamento de Sociología, Universidad de Chile

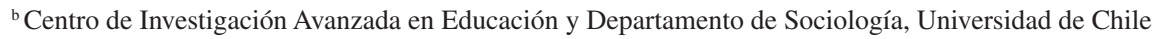 \\ Correo electrónico: cbellei@ ciae.uchile.cl \\ ${ }^{c}$ Centro de Investigación Avanzada en Educación, Universidad de Chile
}

\begin{abstract}
RESUMEN
La propuesta de introducir mecanismos de mercado en educación ha impulsado el debate político y la investigación sobre la elección de escuela por las familias. Chile ha sido un caso paradigmático al respecto, implementando una comprehensiva reforma educacional neoliberal, uno de cuyos efectos más relevantes ha sido una acelerada privatización, especialmente entre sectores sociales medios. El objetivo del estudio fue comprender el sentido que tiene para los padres chilenos de sectores medios elegir un colegio privado para sus hijos, para lo cual realizamos entrevistas en profundidad y grupos de discusión en dos zonas prototípicas de clase media en Santiago. Nuestros hallazgos muestran que las familias deciden orientándose esencialmente por razones sociales, procurando separarse de grupos socioeconómicamente inferiores (considerados riesgosos), lo cual les hace descartar escuelas públicas, gratuitas y no selectivas, y valorar escuelas que ofrecen un fuerte control disciplinario. Criterios educacionales son así supeditados a la búsqueda de segregación socioeducativa.
\end{abstract}

Palabras claves: elección de escuela, privatización educacional, estudios cualitativos, segregación educacional, sentido de la acción social.

\section{ABSTRACT}

The idea of introducing market mechanisms to education has prompted a political debate and research around school choice. Chile has been a paradigmatic case on this, implementing a comprehensive neoliberal educational reform; a relevant effect has been a rapid educational privatization, especially among the middle classes. The objective of this study was to understand the meaning of choosing a private school according to middle class parents. We conducted in depth interviews and focus groups with parents living in two middle class areas of Santiago. Our findings show that parents make decisions mainly oriented by social reasons, trying to avoid lower socioeconomic groups (considered to be risky), which makes them to discard public, free, and non-selective schools, and value schools that offer a strong disciplinary control. Thus, educational criteria are subordinated to the search for socio-educational segregation.

Key words: school choice, educational privatization, qualitative studies, educational segregation, meaning of social action.

Se agradece el financiamiento otorgado por FONDECYT 1130430 y Proyecto Basal FB0003, del Programa de Investigación Asociativa, ambos de CONICYT, Ministerio de Educación de Chile. 
Estudios Pedagógicos XLII, N 3: 89-109, 2016

¿POR QUÉ ELEGIR UNA ESCUELA PRIVADA SUBVENCIONADA? SECTORES MEDIOS EMERGENTES Y ELECCIÓN DE ESCUELA EN UN SISTEMA DE MERCADO

\section{INTRODUCCIÓN: PRIVATIZACIÓN DE LA EDUCACIÓN CHILENA}

Probablemente el rasgo más saliente de la educación chilena en las últimas décadas sea su acelerado proceso de privatización. Si en 1980 alrededor de un 15\% de los estudiantes se educaba en escuelas privadas, en 2014 lo hacía un 60\%; ciertamente, la contrapartida es una drástica reducción de la educación pública a menos de la mitad de lo que era a inicios del período. La expansión de la educación privada es consecuencia de una profunda reforma neoliberal del estado y la economía chilenas (iniciada por la dictadura) que introdujo el libre mercado como regulador de los servicios sociales, incluyendo la educación (Bellei, 2015). Así, las escuelas que reciben recursos públicos en Chile son financiadas por un subsidio per cápita que "sigue al alumno" (voucher), de forma que deben competir por captar las preferencias de las familias, quienes pueden elegir la escuela que prefieran para sus hijos. Este sistema se aplica por igual a escuelas públicas y privadas, persigan o no fines de lucro. En efecto, la privatización ha sido impulsada principalmente por la creación de escuelas privadas subvencionadas con fines de lucro (Elacqua, 2012).

Junto con privatizarse, la educación chilena se ha segmentado socialmente, de forma que el perfil socioeconómico de los diferentes tipos de escuelas es muy marcado: las escuelas privadas que no reciben subvención estatal atienden exclusivamente a familias de nivel socioeconómico alto; las escuelas públicas, principalmente a familias de nivel socioeconómico bajo y medio-bajo; y las escuelas privadas subvencionadas, a familias de nivel medio (Elacqua, 2012; Valenzuela, Bellei y De los Ríos, 2014). Dos aspectos críticos al respecto son que las escuelas privadas subvencionadas pueden cobrar a las familias un arancel obligatorio (hasta un cierto máximo), sin perder el subsidio estatal, permitiéndoseles una amplia libertad de precios; y que pueden seleccionar a los alumnos que desean admitir. Las escuelas públicas, en cambio, son gratuitas y —en última instancia- están obligadas a recibir a todos los postulantes. En definitiva, la privatización de la educación chilena se asocia fuertemente con el abandono de la educación pública por parte de los sectores medios y su aparente "preferencia" por las escuelas privadas subvencionadas. Este artículo busca comprender las razones de las familias que eligen dicha opción.

\section{LA ELECCIÓN DE ESCUELA COMO PROBLEMA DE INVESTIGACIÓN}

Aunque tradicionalmente muchos sistemas educacionales han permitido cierto grado de decisión de los padres sobre dónde educar a sus hijos, solo en las últimas décadas la elección de escuela se ha convertido en asunto relevante del debate de políticas educacionales, al ser incorporada como componente medular para introducir el mercado en educación (Ball, 2003; Duru-Bellat, 2004).

De acuerdo a la perspectiva de mercado en educación, las escuelas debieran competir por las preferencias de las familias, las cuales debiesen tener libertad para elegir el establecimiento educacional para sus hijos. Idealmente, las familias debiesen conocer la "calidad" de las diferentes ofertas y usar dicha información al elegir, premiando así a las mejores escuelas y obligando a las malas a mejorar o a salir del mercado. Cada familia debiese evaluar "racionalmente" las alternativas maximizando el beneficio esperado para sus hijos. Finalmente, es crítico que las escuelas puedan diferenciarse y acomodar su oferta a las preferencias familiares; por eso los proponentes del mercado impulsan la participación 
de oferentes privados; pero, de persistir una oferta pública, esta debiese disciplinarse a la lógica reseñada (Chubb y Moe, 1990; Friedman, 1955). La elección de escuela resulta así el mecanismo dinamizador del sistema educacional.

La implementación en algunos países de las propuestas de mercado en educación ha impulsado desde los 80 un intenso debate académico, en el cual comprender la elección de escuela por las familias ha sido una pregunta central. Básicamente, se ha testeado los supuestos de las políticas de mercado escolar, reconstruyendo la racionalidad electiva de los padres respecto del colegio de sus hijos y anticipando las consecuencias sistémicas de dichas elecciones.

Aunque el debate sigue abierto, la evidencia sobre los efectos agregados de la elección escolar sugiere que no habría tenido un impacto relevante en los logros académicos de los alumnos, pero sí efectos negativos en términos de la segregación social y racial de las escuelas (Bifulco, Ladd y Ross, 2008; Haynes, Phillips y Goldring, 2010; Lauen, 2007; Levin y Belfield, 2006; Witte, 2009). Estos hallazgos han relevado la tensión entre la libertad de elección de las familias y la concepción de la educación como bien público, cuya diversificación de mercado sería perjudicial. Los estudios también han mostrado diversidad en las prácticas de elección escolar de las familias. Esta diversidad no se reduce a desigualdades de recursos económicos, sino que se asocia con diferentes posiciones en la estructura social y configuraciones culturales, especialmente de clase social, raza, etnia y lengua. Así, una comprensión profunda desde la perspectiva de las familias se vuelve imprescindible para entender el potencial transformador de la elección escolar (Ball, 1993; Van Zanten, 2007).

Predominantemente, la clase social de las familias es la característica más relevante para comprender la elección escolar, algunas veces asociada con características culturales como la etnia o la religión (Ball, 2003). Identificada tradicionalmente como una estrategia de las clases altas para conservar y acrecentar sus ventajas a través de la educación, la elección escolar promovida por políticas recientes ha tendido a favorecer a las clases medias. Estos sectores han sido los más activos en aprovechar las nuevas oportunidades de elección, buscando distanciarse de las clases bajas, inmigrantes y minorías étnicas (Alegre y Benito, 2012; Ball, Bowe y Gewirtz, 1996; Dauphin y Verhoeven, 2002; PérezDíaz, Rodríguez y Sánchez Ferrer, 2001; Rambla, 2003; Veleda, 2007; Yoon y Gulson, 2010). Ciertamente, los padres de clase media evitan escuelas que perciben de baja calidad académica, pero frecuentemente esta es inferida por la composición social, étnica y cultural de la escuela, produciéndose un círculo cuya racionalidad es eminentemente sociocultural, antes que académica (Ball y Reay, 1998; Olmedo y Santa Cruz, 2007; Pérez-Díaz et al., 2001; Van Zanten, 2003). En definitiva, esta lógica de elección escolar de las clases medias, sumada a las mayores restricciones que enfrentan las familias de clases bajas, presiona hacia un sistema socialmente segregado y convierte la escuela pública "abierta a todos" en un oferente con claras desventajas en este "mercado" (Ball, 2003; Da Costa y Koslinski, 2012; Raveaud y Van Zanten, 2007; Van Zanten, 2007).

El sistema escolar chileno resulta paradigmático para estudiar la elección escolar en contextos de mercado, sin embargo, existe muy poca evidencia acerca de las prácticas, racionalidades y sentido que las familias despliegan al elegir escuela para sus hijos. Algunos estudios basados en encuestas han producido hallazgos interesantes, pero poco consistentes: mientras Gallego y Hernando (2009) encuentran que la calidad de las escuelas es un factor de gran relevancia para la elección, Carrasco y San Martín (2012) 
y Elacqua y Fábrega (2006) encuentran que no lo es. La investigación cualitativa sobre elección de escuela está también en una fase inicial en Chile. Los hallazgos sugieren que las familias pobres no utilizarían estrictamente un modelo "racional" orientado por la calidad académica, sino que operarían guiadas por consideraciones prácticas (gratuidad, cercanía), de control y protección social, y tradicionales (como el conocimiento previo de la escuela) (Córdoba, 2014; Espínola, 1993; Navarro, 2004; Raczynski y Hernández, 2011). Una limitación importante es que la investigación se ha concentrado en familias de clase baja, en circunstancias que han sido los sectores medios los más directamente involucrados en la privatización por elección escolar en las últimas décadas en Chile. Nuestro estudio aporta a la tarea de cubrir este vacío de conocimiento.

\section{METODOLOGÍA}

El objetivo del estudio reportado acá fue comprender el sentido que para los padres tiene elegir un colegio privado-subvencionado para educar a sus hijos ${ }^{1}$. Asumiendo que la elección de escuela privada está mediada por la subjetividad, por cómo los padres la entienden e interpretan, intentamos comprender el significado de tomar esta opción entre un conjunto de alternativas, lo cual supone reconstruir el sistema de distinciones donde la alternativa elegida aparece diferenciada frente a las descartadas.

La metodología cualitativa está orientada a captar estructuras de significados con que puede describirse prácticas culturales, atendiendo las propias comprensiones y entendimientos de los sujetos de un grupo determinado (Canales, 2014; Taylor y Bogdan, 1987). Accedemos al sentido a través del habla social que lo relata; así, buscamos conocer el discurso con que los propios sujetos se comprenden cuando eligen una escuela privada subvencionada para sus hijos.

Para producir la información requerida por nuestra pregunta de investigación, utilizamos dos técnicas complementarias: Grupo de Discusión y Entrevista Focalizada (Canales y Peinado, 1995). El grupo de discusión apunta a conocer el "buen decidir": cuál es el valor o significado colectivo de la decisión. En nuestro caso, permitió acceder a la representación social de lo que se debe o no se debe hacer al seleccionar escuela. Observamos la lengua o moral grupal que determina lo debido en este ámbito y los modos en que los sujetos lo interpretan (Canales, 2006; Ibáñez, 1979). Las entrevistas focalizadas permiten conocer los usos y prácticas decisionales; cómo el sujeto entiende ("sabe") lo que está haciendo cuando elige escuela (Alonso, 1996; Valles, 2015). Así, mientras los grupos de discusión nos permitieron reconstruir la norma general del elector de escuela privada-subvencionada - el estereotipo-, las entrevistas ayudaron a comprender la heterogeneidad de situaciones prácticas en que esta se pone en juego.

Dado que la mayor expansión de escuela privada-subvencionada se ha producido en sectores urbanos de clase media, decidimos estudiar dos comunas prototípicas del área metropolitana de Santiago: una de ingresos medios y medio-bajos, emergente y de gran crecimiento en las últimas dos décadas; y otra de ingresos medio-altos tradicional de

Este artículo se concentra en los padres de sectores medios que eligen escuelas privadas subvencionadas. El estudio mayor del que forma parte incluyó padres de sectores sociales más altos y más bajos, y que enviaban a sus hijos a establecimientos públicos y privados sin subvención. 
la clase media profesional. Dentro de ellas ubicamos barrios que respondieran al perfil descrito. Realizamos tres grupos de discusión con padres que educaban a sus hijos en escuelas privadas-subvencionadas y eran residentes de las zonas estudiadas: uno con padres que enviaban a sus hijos a establecimientos de arancel mensual gratuito o bajo menor a $\$ 35.000$ - y otro de arancel alto en la comuna de ingresos medios y emergente; y uno con ambas situaciones en la comuna de ingresos medio-altos y consolidada. Cada uno de estos grupos incluía diversas condiciones, tanto de sexo de los participantes, como de tiempo en el establecimiento y nivel educativo de los hijos (enseñanza básica y media). Adicionalmente, realizamos ocho entrevistas en profundidad a padres que enviaban a sus hijos a escuelas privadas-subvencionadas (también heterogéneas) en estas mismas zonas. De esta forma, cubrimos una gran variedad de situaciones y condiciones, incluyendo colegios de distintos aranceles, distinto nivel de selectividad y desempeño. La mayor parte de los padres había matriculado a sus hijos solo en escuelas privadas-subvencionadas, pero algunos habían cambiado a sus hijos desde escuelas municipales. Para obtener información de contexto, entrevistamos a cuatro directores de colegios privados-subvencionados y a tres autoridades municipales y del Ministerio de Educación de la zona estudiada. El trabajo de terreno se realizó durante el año 2013.

El análisis del discurso producido trabajó sobre los dos ejes de la coherencia de significado (Ibánez, 1979; Taylor y Bogdan, 1987). Por una parte, la identificación de paradigmas o elementos que se pueden entender como paráfrasis o metáforas recíprocas, es decir, un conjunto de elementos que redundan sobre un eje de significados y los despliegan en sus múltiples formas; por otra, la identificación del sintagma, o la coherencia lógica y expresiva que pueda haber entre los paradigmas identificados. La coherencia resulta así en la organización de los efectos de sentido en categorías (temas, paradigmas) y secuencias (partes, sintaxis) que como conjunto conduzcan en una misma dirección o sentido. Cada grupo y cada entrevista fue codificado y analizado como una unidad; posteriormente el análisis buscó la comprensión profunda del acto de elegir una escuela privada-subvencionada, enfatizando lo que tiene de común el discurso que lo explica. En consecuencia, los resultados que presentamos trabajan el material empírico mayoritariamente como un todo, reduciendo las diferenciaciones al interior de la muestra a lo que consideramos indispensable. Por cierto, en la realidad (individual y grupal) los elementos identificados se presentan con matices, énfasis y tensiones, pero nuestro propósito fue descubrir el sentido común que les anima, el cual describimos de un modo estilizado.

\section{RESULTADOS ${ }^{2}$}

En lo sustantivo, el elector de escuela privada-subvencionada entiende su elección como distinción respecto de lo que no se quiere ser: el mundo popular; solo una variante minoritaria, asociada a las escuelas más caras, la comprende como principio de integración a lo que quiere llegar a ser: la clase media de altos profesionales. El principio normativo común es la elección de escuela como acto de constitución de clase o estamento. En lo

Para la referencia de las citas de los entrevistados, el código GE1 corresponderá al grupo de arancel bajo de la comuna emergente, GE2 al de arancel alto de la misma comuna, y GC1 al grupo de la comuna consolidada. Aunque el análisis integró el material de entrevistas, por razones de espacio, hemos optado por presentar citas solo de los grupos de discusión. 
estratégico, antes que elegir una escuela, el elector de escuela privada-subvencionada elige este "tipo de escuelas" distinguiéndolas de las públicas, a las que rechaza como grupo, y de las privadas no subvencionadas a las que asume como ajenas.

La elección de escuelas está — para estos padres - fuertemente enmarcada por tres restricciones: el precio (especialmente de las escuelas privadas sin subvención), la distancia y la selectividad académica (en este último caso de algunos colegios públicos que operan con elevados requisitos de desempeño bajo una lógica de selección "meritocrática"). Así, estos padres tienen clara consciencia de que las escuelas a las que acceden no son parte de la elite social ni académica.

A continuación desarrollamos los componentes discursivos que articulan el sentido de la elegibilidad de las escuelas privadas subvencionadas para estas familias, agrupándolos en tres ejes: los socio-tropismos involucrados, la búsqueda de orden y control y la orientación hacia el futuro. De estos elementos surge una clara norma social, en el sentido que sus códigos se repiten en entrevistas y grupos de discusión, resulta coherente, altamente racionalizada y enraizada en las prácticas de los sujetos.

\subsection{SOCIO-TROPISMOS}

Fundamentalmente, se elige escuela privada-subvencionada buscando la segregación motivada por una socio-fobia que rehúye el contacto con la turba o mezcla de las escuelas públicas; y por una socio-filia que busca la congregación protectora del encuentro entre homogéneos.

\section{Todo revuelto: la turba}

El discurso dominante entre quienes eligen colegio privado-subvencionado alude a una "separación", segregación respecto de otros y congregación entre sí. Los padres creen que la educación de sus hijos conlleva un riesgo importante, el de la mezcla, riesgo que intentan controlar. La base de su malla representacional distingue entre escuelas que "seleccionan" y que "mezclan"; así, las escuelas pueden ser la solución o el problema, según hagan o no esta partición: al hacerla, contribuyen a controlar el riesgo social de la mezcla; al mezclar, reproducen la potencia peligrosa de aquella. Ubicados en la parte inferior de un sistema educativo socialmente estratificado, les parece vital separarse de aquellos lugares donde se hace la última exclusión, donde llegan los que no tienen más caminos.

Que al municipal supuestamente llega de todo, todo lo que los colegios rechazan. GE1.

Pero por eso es un colegio problema ese colegio, porque reciben a todos los niños que echan de otros colegios. GE2.

El peligro está en el conjunto que incluye a todos, porque trae el mal consigo como una "mala junta".

Sí, baja mucho el nivel, el ambiente... Yo tuve un nieto ahí tuve que irlo a retirar porque no estaba teniendo buenas juntas. Como que llegaban los que eran más desordenados. GE2.

Es una repulsión de la revoltura: donde llega de todo, llega caótico y turbio. 
[...] lo que pasa es que de repente uno le da a los niños, lo que me pasa a mí con el colegio, le da valores le da todo, pero en ese colegio, ha llegado de todo, todo revuelto, todo revuelto. GE1.

Este rechazo produce discursos de higiene social, marcando el punto de separación entre lo sucio y lo limpio.

[...] estaban admitiendo mucho, mucho pelusa, pelusas prácticamente, estaba de muy mal, cómo se dice, fama, muy mala fama, pero se puso el director, donde tenía que ponerse y empezó a limpiar, a limpiar y ahora, gracias a dios, tenemos un ambiente muy bonito, la gente es bien humilde, pero son mamás muy preocupadas de los niños y los chicos son educados. GE1.

Así, no solo se nombra la partición, se la aplaude como una conquista: llegar al colegio privado-subvencionado es haber escapado de la mezcla barrial por la vía segura de la autocongregación de los buenos entre los mundanos.

Miedo al otro: el "flaite" 3

En el núcleo de esta fobia a la mezcla está el temor al flaite, quien simboliza el extravío social, asumido de un modo activo y provocador. Para los electores de escuelas privadassubvencionadas, los colegios públicos arrastran el apelativo de flaite, por lo que deben ser rechazados.

Es que el nivel de ella es distinto, lo hubiera pasado mal, porque decía que son todos flaites en [menciona un colegio público], flaite, muy flaite. GE1.

Lo flaite es la potencia cultural del marginal: donde llega instala su ley, que por seducción o fuerza termina por imponerse. El flaite crea un régimen cuyos criterios se muestran acaso más sólidos que los de los integrados. Esa sería la falla de los colegios públicos, que en vez de socializar y educar en la cultura legítima, quedarían dominados por la marca marginalizante de estos estudiantes.

El niño llegaba todos los días tironeado, lo escupían. Y para que lo aceptaran comenzó a hacer las mismas maldades que los otros, así por abacanarse como dicen. GE1.

El gesto flaite no es el del necesitado, sino del provocador, indicio de deserción delincuencial. Lo irritante del flaite es que transforme su debilidad en soberbia, mostrando un potencial contracultural. Entonces, el miedo y desprecio es total cuando el otro se despliega culturalmente, alcanzando incluso la fonética. No es solo lo que dicen, sino cómo lo dicen, especialmente en el "sonido", indicio de consistencia cultural en la transgresión simbólica.

Siempre están fumando, siempre están pidiendo plata, es así como que te da susto pasar por el mediol es así como "me da una moneda" [imitando la voz de flaite]. GE2.

Uso popular para referirse a personas de posición inferior en la estructura socioeconómica, con orientación hacia el consumo ostentoso. El flaite es, además, desafiante, porque rechaza la humildad, gesto socialmente obligado para estos estratos. 
Así, los flaites son un modo dos veces perdido: por pobres y por indignos. Incluso entre los caídos en la dignidad social (como los alcoholizados o vagabundos), el flaite sobresale por su falta de humildad. De ahí la acusación moral: una cosa es ser pobre, otra ser flaite.

Yo digo por qué eso, siempre yo he hecho esa pregunta, no será, bueno por el socio-económico bajo, será, que los papás, no sé, yo siempre he tenido eso, porque eso no importa, yo digo ser pobre, pero ser educadito. Yo la verdad es que no entiendo eso. GE2.

En definitiva, el flaite es el "mal pobre", que en lugar de aceptarse en sus circunstancias, se levanta como modelo. Para familias de clase media-baja, encontrarse con el flaite es sentir su resoplido como fantasma que habita el mundo del que se está precisamente saliendo. Ese miedo es lo que despierta el colegio público, y es lo que moviliza hacia una escuela privada-subvencionada.

\section{Marcar la diferencia}

La elección de colegio privado-subvencionado está en la moral del grupo identificado como "clase media emergente". El hecho mismo de elegir un colegio en que se paga expresaría una marca de calidad social, es decir moral, de las familias y, por transitividad, del colegio. La selección que los colegios hacen como control de la mezcla turbia se refuerza ahora como semiótica del buen padre, responsable y comprometido, redondeando así la tautología social: estos colegios son buenos pues a ellos concurren las buenas familias del lugar.

Pero a veces uno ve que hay gente que puede pagar un poco más y manda a los hijos a colegios municipales donde va pura gente con malas costumbres; entonces como que uno ve que no se preocupan mucho, que no les importa... y quizás con pocas lucas podrían encontrar un particular subvencionado, que ya marca una diferencia. GE1.

Estas familias eligen pagar y pagan por elegir, y en esta acción se marcan como distintos. Aun si la escuela privada-subvencionada no ofreciera nada más, ya tendría instalada su capacidad de atracción. Lo opuesto a la turba es, ahora, la diferenciación señalada por el pago.

Para qué andamos con cosas, el hecho de pagar, aunque sea un poco, igual marca la diferencia. GE2.

Como se ve, elegir un colegio privado-subvencionado es para estas familias al mismo tiempo un deber — quien pudiendo no lo hace queda en deuda o en duda - y un ideal quien lo hace recibe el reconocimiento interior del deber cumplido-. Se trata, en suma, de un modo de actuar socialmente vigilado y positivamente sancionado.

Socio-filia: homogeneidad (moral) de las familias

Los colegios son así considerados no tanto como organizaciones educativas, sino como comunidades de crianza. Se eligen escuelas que eligen a familias que dan prueba de su consistencia moral. Más que educación, lo que se paga son las condiciones del tiempo social de la niñez y adolescencia en la escuela. 
Que lleguen niños de hogares bien, cómo dijera, con mucha educación, con mucha preocupación de sus padres sobre los niños. GE1.

La elección de escuela privada-subvencionada se transforma en medio y signo de la profilaxis respecto al miedo al extravío social. Un medio, porque es el mecanismo selectivo de las escuelas lo que produce la segregación; y un signo, pues es sobre la auto-selección para postular a un colegio privado-subvencionado donde se sostiene la coherencia de la congregación de los responsables. Para estos padres, las escuelas privadas-subvencionadas producen así congregaciones basadas en la segregación interna de un mismo estrato social, separando a los incluidos o en proceso de inclusión, de los extraviados o en camino de serlo.

Del nivel socio-cultural, no en tanto a la plata, a la plata que tienen los papás digamos, sino que a nivel como de, educacional, por decirlo así, de los niños, o sea, de la forma de expresarse, de cómo andan vestidos. GE2.

La clave está en reconocer y buscar la coherencia entre tipos morales de personas y tipos de colegios.

Es malo, desordenado, se nota que es para otro tipo de personas, no digo gente mala, ni nada de eso, pero gente que no tiene la misma preocupación por los niños. GE2.

La educación se juega en el "nivel socio-cultural" de las familias de la escuela, definido esencialmente por la disciplina moral de los sujetos. En el colegio, la escena básica no es el estudio, sino el contacto, por eso un buen colegio es el que protege del contagio.

Que los papás no están ni ahí, les da lo mismo y por eso de repente, no sé po', los embarazos escolares, todas esas cosas... y yo no quiero que mis hijos estén viendo o como educándose con cierto tipo de gente. GE2.

Así adquiere sentido la selección que hacen las escuelas, filtrando no ya a los buenos estudiantes, sino a las familias rectas: la sociología antecede a la calidad educativa. El colegio se elige por sus dispositivos de homogeneización moral sobre las familias que admite.

Preguntan mucho por el hogar, qué costumbres hay, cómo se porta el papá, la abuela, en fin, para ver el entorno del niño. GE1.

Es interesante advertir que las familias de escuelas privadas-subvencionadas más caras también atribuyen un carácter moral a la frontera que les separa de los colegios privados no subvencionados (de precios para ellas inalcanzables). Así, se autoperciben como la gente sana entre dos "disfuncionalidades": la inseguridad ciudadana (por abajo) y la crisis moral (por arriba).

Entonces, por distintos motivos, pero al final en ambos polos, se repiten malas conductas. /En ambos extremos se producen las mismas conductas que están avaladas por cierta impunidad. En el extremo más bajo social, la impunidad es que soy menor de edad, nadie me puede hacer nada. Hago lo que quiero, la ley no me toca. $Y$ en el extremo súper alto, hago lo que quiero, 
tengo plata, compro a quien quiero. /Es más disfuncional... /Claro es disfuncional y para el otro lado es igual. GC1.

Hacia arriba, la elección de escuelas muy caras es descalificada por un afán segregatorio de una clase/etnia superior: los cuicos $^{4}$.

Yo he pasado por ahí de repente y he entrado al colegio y hay mucho, no sé po', es medio cuico: rubios de ojos azules, como dijo mi hija. GE2.

Paradigma del consumo ostentoso aplicado ahora a la educación, son colegios que no pueden pagar y a los que no quieren aspirar.

No, lo que buscan es el estatus: "mi hijo está en el mejor colegio”. GE2.

Para estos padres, en cambio, pagar la escuela es una expresión de la resiliencia y sacrificio con que el mundo popular se auto-identifica, canalizados como esfuerzo para pagar una colegiatura y postergar otros gastos.

Lo normal viene a ser entonces la posición media. Los colegios públicos, aunque elegibles, son descartados por sus riesgos sicosociales; las escuelas privadas no subvencionadas, aunque no elegibles por su alto precio, tampoco dicen desearlas, por su elitismo y omnipotencia. Es un discurso de identidad y elogio de la clase media en que se reconocen. Así, lo que comienza como analogía termina afirmando una correspondencia ya naturalizada entre tipos de escuelas y clases sociales: privadas, privadas-subvencionadas y públicas, y clases alta, media y baja. La escuela privada, pero subvencionada, les confirma su nivel, ni inferior ni superior.

Sí, encuentro que sí me acomodan... Fíjate que esto de que los visualicemos como que están un poco al medio, también quiere decir que están un poco al medio de los otros dos extremos. Es como que nosotros somos de clase media, y estos colegios están al medio. GC1.

En definitiva, los colegios privados-subvencionados son los colegios de las familias de clase media, quienes pueden y se esfuerzan en pagar algo para no caer en el desprestigiado e inseguro colegio público, pero no pueden pagarlo todo para acceder a los clubes-colegios de la elite que igual miran con sospecha. Como a virtuales "clientes cautivos", la categoría de escuelas privadas-subvencionadas les viene prácticamente pre-seleccionada.

Es que es nuestra realidad, y el colegio la representa, yo creo que cada uno debe buscar colegios para sus hijos que vayan de acuerdo a su realidad. GC1.

\subsection{BÚSQUEDA DE ORDEN Y CONTROL}

El segundo eje que organiza la elección de escuelas privadas-subvencionadas es la búsqueda de la seguridad asociada al buen gobierno y estricto control. Sobre el estereotipo del colegio público abandonado, sin estándares básicos de gestión, se prefiere instituciones que ofrecen calidad organizacional respecto a las instalaciones, las rutinas y, en especial, el mantenimiento

Expresión con connotación negativa, referida a personas ostentosas de clase alta. 
de la disciplina y la uniformidad. Altamente valorada es la escala pequeña que permite ofrecer comunidades de control personal, reforzando la noción de protectores comunitarios.

\section{Mantención del orden}

El mantenimiento del orden organizacional resulta central para quienes eligen escuelas privadas-subvencionadas. Antes que a la "excelencia académica" (slogan ampliamente utilizado como marketing educacional), los padres refieren a la suficiencia de los colegios en su capacidad de autogobierno. En lo físico.

Yo también encuentro que es bueno, es grande eso sí, pero no se ve mal colegio, está bien tenido. GE1.

En lo administrativo.

Sí, muy organizado, muy buen colegio. GE2.

En la conducta institucional.

El colegio particular subvencionado tiene que mantener un nivel... porque el colegio particular subvencionado tiene que mantener una línea. GE1.

Estas familias perciben que los colegios entre los que pueden optar también están amenazados (como las escuelas públicas) por tendencias entrópicas; en ese contexto, los privados-subvencionados les ofrecen una eficacia auto-correctiva como sello institucional.

\section{Control disciplinario}

Para estas familias, la clave del orden escolar es el gobierno de los estudiantes, su disciplinamiento. Evalúan de manera formalista y rigorista la disciplina en la institución educativa, con claras resonancias morales de elogio y culto a la autoridad. Las escuelas privadas-subvencionadas se muestran rígidas y altamente estructuradas.

Es muy buen colegio, mi hija estuvo ahí, hay una estructura bien fuerte, una enseñanza pero muy linda. GE1.

El orden no solo se valora: la emocionalidad involucrada en esta dimensión es patente. El rigor gusta, así como el imperio de la ley.

Lo que aquí me gusta es la ley, es tan estricto. GE1.

La disciplina es también un símbolo que debe lucirse; por eso es tan importante el uniforme, que ordena la vestimenta y formaliza un aspecto moral: el signo (la falda en este caso) se mide en centímetros.

Decentitos, no se le permite la falda cortita, tiene que ser dos dedos arriba de la rodilla o si no, no. GE2.

En el trasfondo de esta exaltación del control de los estudiantes resuena el fantasma del caos de la turba; la educación que ofrecen las escuelas privadas-subvencionadas es primeramente un modo de desactivar las múltiples tendencias al desorden, al extravío. 
Uno busca un colegio que sea como estructurado, con reglas, disciplina, con toda esa situación para los niños, porque si se fijan, hoy en día hay muchos chicos que se pierden. GE2.

El orden que promete la escuela opera como segundo muro de protección respecto del exterior difuso y callejero. El pastoreo (que remite a la educación católica, paradigma histórico de las escuelas privadas en Chile) aparece como fórmula análoga a la inspección: congregación hacia adentro y segregación del afuera, percibido ahora como el mundo y sus riesgos.

Tiene mucho lo que es pastoral. Es que cuando son niñas, uno siempre trata de protegerlas del afuera del colegio. GC1.

Así, las dinámicas selectivas y auto-selectivas de las escuelas privadas-subvencionadas, se complementan con un dispositivo de control disciplinario que garantiza el orden, no tanto como medio, sino como propósito de la educación socializadora que ofrecen.

\section{Pequeña escala: seguridad y calidez.}

En algunos casos, las escuelas privadas-subvencionadas son valoradas porque ofrecen una organización de menor escala, más fácil de controlar y de trato personalizado. En el imaginario de estos padres, las contrastan con colegios públicos masivos, impersonales y caóticos. Tan importante es este aspecto que se le puede esgrimir como razón para elegir una escuela, descrita con la calidez asociada a lo diminutivo.

Mira, es un colegio pequeñito. Tiene pocos alumnos de matrícula total... Son cursos chiquititos. $Y$ bueno, esa fue una de las primeras cosas que a mí me atrajo para matricular a mi hijo ahí. GC1.

También puede convertirse en el argumento para cambiar de colegio, sugiriendo como autoevidente la inconveniencia de la numerosidad en el proceso educativo.

A mí eso fue lo que me ayudó a tomar la decisión [de sacarlo de ese colegio]. La cantidad de alumnos, porque tiene mucho niño. GC1.

¿Qué hay detrás de esta defensa de la pequeña escala escolar? Para estas familias, los grandes números son figuras frías y hasta temibles; el colegio masivo no es solo mezcla, también disolución de la individualidad del sujeto. Las escuelas públicas son identificadas por un número y las privadas se distinguen por poseer nombres; estos padres, por analogía, aplican esta distinción a los alumnos.

Eso es lo otro, un colegio puede ser muy bueno, pero si son muy grandes, tu hijo es un número más [...] Imagínate, para uno son sus guaguas y para ellos, un número. Eso como que angustia harto. GE2.

Así, un buen colegio no basta si se es "un número más". Nuevamente, lo que está en juego es un asunto más básico que lo pedagógico: se trata de la seguridad, del cuidado de los hijos. 
Es uno más y eso se nota más en los municipales. Es importante saber que tu hija es bien cuidada, que si es chiquitita no va a correr peligro, y que siempre va a haber una persona grande que sabe dónde ella está. GE1.

Para estos padres, la selección impide que "entre cualquiera” y la gestión personalizada de estas escuelas garantiza luego que sus hijos no serán tratados como cualquieras. Así, la pequeña escala asociada con el colegio privado-subvencionado funge en un sentido social como seguridad y en sentido educativo, como personalización.

\subsection{UN FUTURO VIABLE}

Finalmente, la elección de colegio también incorpora expectativas sobre el resultado del proceso educativo, una cierta imagen del futuro. Las familias que eligen escuelas privadassubvencionadas parecen conformes con las posibilidades que se presentan para sus hijos según sus logros en la educación primaria-secundaria. El asunto capital aquí es la consistencia decisional, basada en la expectativa de continuidad de estudios en universidades o institutos académicamente no selectivos. Un futuro bueno y — sobre todo- realizable, para el que no se precisa un desempeño académico destacable. Las escuelas privadas-subvencionadas parecen cumplir su promesa sin necesidad de producir rendimientos competitivos, pueden ser incluso similares a los colegios públicos y no por ello estar(les) fallando.

\section{El camino}

La imagen de fondo apela a consolidar el proceso de integración a la sociedad, como si estas familias no lo dieran aun por asegurado. Así, hay caminos proyectados fundados en nociones genéricas y aun "civilizatorias". La aspiración expresada con la fórmula minimalista de "llegar a ser alguien en la vida" connota un deseo de inclusión subjetiva plena, como conquista de la dignidad social, más que un norte promocional.

\section{No sé, la idea es que pueda ser alguien en la vida. GE1.}

El futuro deseado es que los hijos refuercen la norma de las normas, sentido del deber y la rectitud. En este proyecto de ambiciones tan fundamentales como básicas, los colegios contribuirían a evitar el descarrilamiento de los jóvenes respecto del camino definido por la familia.

Qué espero... bueno, que ellos sigan teniendo el mismo camino que uno les ha inculcado. GE1.

En abierto contraste con la educación moderna como ventana al mundo y trampolín movilizador más allá de las limitaciones familiares, acá es la familia la que encamina y el colegio apenas el que no descarrila. Para estos padres, la potencia (trans)formadora de la escuela ha sido reducida a su forma protectora de muro y encaminamiento.

\section{Rendimiento}

Las familias también consideran el rendimiento académico en las escuelas privadassubvencionadas; sin embargo, lo hacen con fórmulas genéricas, remitiendo a un criterio 
evaluativo de suficiencia, como recordando que ese aspecto no ha sido olvidado. De hecho, la dimensión académica tiende a subsumirse en la visión holística del orden y no aparece nunca por sí misma como factor decisivo, sino como parte de una totalidad que va del rendimiento a la conducta, y de la conducta al ambiente.

Aparte que la... bueno, la formación académica también es buena; pero como te digo, la formación en complemento... GC1.

Incluso cuando se alude a la medición oficial del rendimiento educacional (nos referimos al SIMCE, ampliamente difundido para que los padres lo usen como indicador comparativo de calidad al elegir escuela), se la refiere de modo difuso, discursivamente intrincado (por lo pronto, nunca se menciona un puntaje SIMCE como indicador objetivo de competitividad académica), y siempre con condicionantes.

Muy bueno, muy exigente, en el SIMCE igual le va bien, a nosotros como papás siempre estamos comprometidos con el colegio, o porque nos integran, es como más familiar. GE2.

La idea de que los colegios privados-subvencionados no son generalmente valorados por su productividad académica se ve paradojalmente reforzada cuando los padres mencionan algunos cuya oferta es precisamente el rigor académico. No solo porque estas escuelas son referidas como excepciones, sino porque el énfasis se pone en la percepción de los padres sobre la selectividad académica en la admisión. Interesantemente, esta selectividad a veces asume la forma de un rumor.

Están pidiendo, por lo menos en [nombra colegio], promedio 6 y con examen... ahí comencé a insistir... [Moderador: ¿postuló y quedó?, ¿fue fácil?] No, para nada. GE1.

Más aun, la centralidad de la selección de alumnos no se limita a la admisión, sino atraviesa toda la escolarización. Así, el filtro de la entrada se reproduce luego como un colador interno por donde van saliendo aquellos que no pueden seguir el ritmo.

Como yo decía, en cuanto a materia, es muy exigente, es muy, muy exigente, inclusive cuando llegan a $8^{\circ}$, hacen un pequeño colador. GE1.

En una espiral de prestigio, un colegio aumentaría su atractivo en la misma medida en que - por alta demanda- pudiera elegir a sus alumnos y hacerlo en procesos de gran competitividad y riesgo. Al mérito de los padres (que pueden y quieren pagar la diferenciación) se suma el mérito del hijo, ganándose su propia diferenciación.

\section{Profesionales}

Las referencias moralizantes y el desperfilamiento de la calidad académica no implican que estos padres hayan renunciado a que sus hijos sean profesionales, imagen paradigmática de una trayectoria escolar satisfactoria. Al contrario, quienes educan a sus hijos en escuelas privadas-subvencionadas los proyectan en institutos profesionales y universidades. Ocurre aquí uno de los fenómenos más interesantes del nuevo imaginario social chileno. 
La expansión de las escuelas privadas-subvencionadas es parte de la misma reforma de mercado que promovió la creación de universidades privadas académicamente no selectivas e institutos profesionales privados. Incluso, estos tres tipos de instituciones comparten en buena medida su "mercado objetivo". Ese maridaje histórico-social es sustancial para su comprensión: crecientemente, universidades e institutos privados son el complemento de sentido de los colegios privados-subvencionados. Literalmente:

Pucha, que sea feliz, que salga de 4to Medio tranquilo y que entre a la Universidad. Yo sé que va a entrar a una Universidad Privada, pero... y no es por desmerecerlo. GC1.

\section{Referencialmente:}

Mira, mi hija cuando salió estudió Ingeniería en administración y en ejecución turística en el..., la fui a matricular al [Nombra un Instituto Profesional]. GC1.

Pero, sobre todo, difusamente:

Bueno, es que tú siempre, si colocas a tu niño en un particular subvencionado o en un particular, quieres siempre que entre a una universidad. GE2.

Así, en el habla cotidiana "la universidad" es cada vez más una institución privada noselectiva de reciente creación y quien quiere referirse a las universidades "tradicionales" (más selectivas y prestigiosas) remarcará la diferencia con el adjetivo. Este efecto de asociar difusamente "universidad" con "universidad privada" se redobla con los "institutos":

Yo espero eso, la Universidad. Lo que ella quiera en realidad, si le gusta una carrera de un instituto, que estudie ahí. GE1.

En definitiva, que sus hijos sean profesionales se ha vuelto algo accesible para estas familias, gracias a la oferta privada académicamente no selectiva. Sin este canal para continuar estudiando, la oferta que hacen las escuelas privadas-subvencionadas probablemente habría encontrado una falla de consistencia, dada la enorme expansión de las expectativas por acceder a la educación superior. Por eso, aunque saben que sus hijos no asisten a los colegios "de la elite" económica ni académica, los padres de escuelas privadas-subvencionadas se sienten reconfortados.

No, yo estoy tranquilo. / Yo igual. / Sí. / Yo creo que fue lo mejor que pudimos hacer, aquí y ahora, te digo que creo que es lo mejor que podemos darles. GE2.

\section{DISCUSIÓN}

\subsection{EL SENTIDO DE ELEGIR ESCUELA PRIVADA-SUBVENCIONADA EN EL MERCADO EDUCACIONAL CHILENO}

De acuerdo a nuestro análisis, elegir una escuela privada-subvencionada no es fruto del error, el engaño o la mera desinformación, sino el resultado razonado de una pauta de acción orientada consistentemente. El sentido de esta elección, sin embargo, no se encuentra en la racionalidad que inspira oficialmente la institucionalidad del mercado 
educativo; i.e. buscar la mejor relación precio/calidad, entendida como la producción de desempeños académicos competitivos que permitan acceder a universidades/profesiones de prestigio, satisfaciendo una aspiración de movilidad social ascendente. Lo que dinamiza el mercado escolar chileno no es la compra/venta de calidad educacional.

A cambio, los colegios privados-subvencionados ofrecen una promesa de protección y control social de los hijos, por la vía de evitar el riesgo asociado a la mezcla con sectores sociales inferiores y asegurar orden y control disciplinario en la escuela, aspectos percibidos como ausentes en la educación pública. Logrando que los estudiantes no "descarrilen" durante su crecimiento y logren un desempeño académico básico, las escuelas privadassubvencionadas satisfacen a sus padres, quienes no se orientan por aspiraciones de movilidad social amplia, sino de estabilización del estatus adquirido y movilidad corta hacia profesiones/universidades de baja selectividad y prestigio. Se diría que lo que mueve este mercado escolar es la compra/venta de seguridad y, finalmente, segregación social.

La fisonomía actual del sistema educacional chileno es la resultante de estas dinámicas de mercado socio-educativo recurrentemente realizadas por más de tres décadas, y por tanto, perfeccionadas. En series sucesivas de elecciones, este mercado se auto-produce, de forma que lo que observamos son prácticas sedimentadas y discursos sociales refinados. Tres elementos clave para su funcionamiento son el desprestigio de la educación pública, el sistema de co-pago y la selección que las escuelas hacen de las familias/alumnos (Bellei 2009; Elacqua, 2012; Mena y Corbalán, 2010; Valenzuela et al, 2014).

Mientras más extendido es el rumor sobre el desgobierno e inseguridad de las escuelas públicas, mayor es el mercado potencial de las escuelas privadas-subvencionadas, mayor su demanda, mayor su rango de precios, y más factible implementar procesos de selección/ expulsión de alumnos/familias (Bellei, González y Valenzuela, 2010). En el siguiente ciclo, esta vez como profecía autocumplida, las escuelas públicas se ven desproporcionadamente atendiendo alumnos más pobres y con dificultades académicas o conductuales, todo lo cual proporciona más combustible para el próximo ciclo. De esta manera, cada año la realidad educacional se asemeja más a las percepciones, transmutadas en imágenes de marca, con precios y niveles de accesibilidad asociados.

Esto permite comprender una aparente paradoja del mercado escolar chileno, cual es que las familias hayan mostrado tanta disposición a pagar por colegios que no poseen mayor efectividad educativa que la escuela pública (Bellei, 2009; Mizala y Torche, 2012; Saavedra, 2013). En la medida en que se instala un "mercado racional" de segregación y seguridad, la dimensión académica de la educación resulta crecientemente irrelevante para oferentes y demandantes. De hecho, las familias tienden a asimilar la educación institucional (moderna) a la crianza comunitaria (tradicional).

Además, esto ayuda a explicar por qué, a pesar de su enorme dinamismo, el mercado escolar chileno no ha mejorado el desempeño de los estudiantes (Bellei, 2015; Hsieh y Urquiola, 2003). En sus discursos los padres prácticamente no hacen referencias al logro académico, mucho menos al currículum o métodos pedagógicos, como si lo educacional fuese algo ajeno a la elección de escuelas privadas-subvencionadas. Pareciera como si, sotto vocce, cuajara una adaptación recíproca de oferta/demanda plenamente consciente de que la competitividad académica no es un producto disponible para ese estrato social, tan distante de las escuelas de la elite. La pretensión tecnocrática de que las familias comparasen escuelas/precio por sus puntajes SIMCE resultaría así en una micrométrica absurda (este "consumidor racional", por cierto, no lo encontramos en nuestra muestra). 
Más costo efectivo resulta para estos padres concentrarse en donde sí pueden hacer una diferencia: esforzarse por pagar un poco más y obtener con ello escuelas muy distintas a las públicas, no en calidad educativa, sino en composición socio-educativa (Valenzuela et al., 2014). Al fijarse en el precio y la selectividad de las escuelas, las familias se informan de los indicadores esenciales para obtener lo que buscan. La paradoja resulta en ironía toda vez que, mientras menos las escuelas se preocupen por "agregar valor" educativo y se concentren exclusivamente en la segregación/selección, los desempeños de los alumnos tenderán a reflejar más exactamente la composición social de las escuelas, produciendo la ilusión de un mercado escolar ordenado por la calidad educacional (Contreras, Sepúlveda y Bustos, 2010; Hsieh y Urquiola, 2003; Mizala y Torche, 2012).

\subsection{ESCUELAS PRIVADAS-SUBVENCIONADAS Y NUEVOS SECTORES SOCIALES MEDIOS}

La distinción social identificada produce una dinámica segregadora al interior de sectores sociales con condiciones de ingreso e inserción ocupacional grosso modo equivalentes. Entonces, donde este mercado sí parece haber tenido un impacto profundo es en la autoconciencia de la clase "media-baja": las escuelas privadas-subvencionadas operan como señal de este estrato recientemente emergido, que se protege allí del riesgo de desintegración que asocia con las familias que educan a sus hijos en colegios públicos y las que no pueden o no quieren pagar por la escuela. Refugio de quienes ya no son pobres, pero que tampoco pueden reproducirse con la tranquilidad de los plenamente integrados.

Complementariamente, las familias que educan a sus hijos en escuelas privadassubvencionadas tienen claro que un mundo socio-económico les separa de quienes asisten a colegios privados no-subvencionados; también saben de su distancia en el rendimiento respecto del grupo de colegios públicos "emblemáticos" de alta selectividad académica. Sin embargo, estas (enormes) brechas sociales y académicas "hacia arriba" no les inquietan mayormente, en la medida en que han asumido un proyecto de consolidación de estatus para el cual las escuelas privadas-subvencionadas les parecen suficientes. En definitiva, la inhibición de la lógica promocional no conlleva un fatalismo marginalista, sino el conformismo de un estrato beneficiado por una trayectoria reciente de ascenso.

Ambos fenómenos se relacionan con cambios mayores en la estratificación social chilena. Las transformaciones estructurales de las últimas tres décadas en Chile han producido una modificación profunda en la dinámica de las clases sociales, especialmente en la zona media (Espinoza, Barozet y Méndez, 2013; León y Martínez, 1998). Los viejos sectores medios se reconvierten (dado el retroceso del Estado en la economía) y la tercerización del trabajo incorpora amplias franjas sociales a ocupaciones de servicio. Los cambios en la estructura ocupacional se asocian con la expansión educacional postsecundaria, aumentando los profesionales universitarios y técnicos, de la mano del sector privado como mercado laboral y mercado educacional. Este proceso es generalmente interpretado como movilidad social ascendente y mesocratización (Torche y Wormald, 2004). En el caso chileno, a nuestro juicio, la calificación profesional en instituciones no selectivas, el aumento general pero moderado de los ingresos, y la inserción ocupacional en la economía terciaria pero no de alto prestigio, aparecen como rasgos de una nueva clase trabajadora.

La fuerte auto-identificación de los segmentos estudiados con la "clase media" no señala una aspiración hacia arriba, sino más bien la legitimación de posiciones (con 
esfuerzo) conquistadas. Más que palanca de movilidad, la educación es vista como defensa ante las posibilidades ciertas de re-caída. En efecto, la evidencia muestra la volatilidad de la situación social de los segmentos medio-bajos (OCDE, 2010); colindantes con la pobreza, esta es para ellos un riesgo siempre presente, por características estructurales de la economía chilena (enorme concentración de la riqueza, homogeneidad de ingresos del percentil 80 hacia abajo, e inestables condiciones laborales) (Castro y Kast, 2004; Ruiz-Encina y Orellana, 2011). Vinculada al problema de clase, la educación privada-subvencionada se transforma en un blindaje de estos sectores ante las capas sociales más bajas. Así, la elección de colegio privado-subvencionado atiza la maduración sociodemográfica del segmento "medio-bajo", que reivindica la legitimidad de su posición rechazando con igual fuerza ser confundido con el "flaite" popular de la escuela pública y con el "cuico" elitista del colegio privado financiado exclusivamente por las familias.

En definitiva, la elección de escuela privada-subvencionada está estrechamente vinculada con las transformaciones en la estructura de clases chilena. La voz del elector de colegio privado-subvencionado expresa la conformación de "nuevas capas medias", la relevancia de la educación en este proceso, y las consecuencias para la vida cotidiana de las relaciones entre Estado y sociedad propiciadas por políticas neoliberales, en este caso, hacer funcionar la educación como un mercado.

\section{CONCLUSIÓN}

La elección de escuelas privadas en un sistema regido por el mercado como el chileno se alinea sensiblemente con preocupaciones de orden social, específicamente, el interés de sectores medios de distanciarse y diferenciarse de los más pobres, a quienes se asocia con las escuelas públicas o gratuitas. Esta elección escolar de base clasista ha sido también reportada por la literatura internacional. Nuestro estudio muestra cómo estas tendencias se canalizan ampliamente y manifiestan abiertamente en una espiral de reforzamiento de las dinámicas de mercado y la segregación socioeducativa de las escuelas. Esta racionalidad social de la elección de escuela predomina y resignifica las referencias a cuestiones propiamente educacionales involucradas. La fragilidad de la integración social de vastos segmentos sociales proyecta en la educación temores y desconfianzas ampliamente diseminados en Chile (PNUD, 1998, 2002); los dispositivos del libre mercado (i.e. competencia entre escuelas, privatización de las relaciones escuela-familia, discriminación por precio, proveedores con motivación de lucro, elección de escuelas) no solamente no inhiben estas tendencias, sino las potencian usándolas como su leitmotiv.

Desde la perspectiva de política educacional, estos hallazgos no dan soporte empírico a las predicciones de los proponentes del mercado en educación, por cuanto ni familias ni escuelas parecen orientarse hacia aumentar la calidad educacional. Más aun, la evidencia analizada permite asociar la elección de escuela privada-subvencionada con efectos indeseados sobre la equidad educacional, especialmente la segregación social, la exclusión de alumnos menos aventajados y la estigmatización de escuelas públicas y gratuitas. La profundidad sociocultural de los fenómenos involucrados sugiere que una agenda de políticas educacionales orientada a revertir estas tendencias (arraigadas por más de tres décadas de operación) enfrentará enormes dificultades institucionales y resistencias sociales. Esto es especialmente crítico dado que la alternativa a este orden de cosas, es 
decir, una escuela pública, gratuita, de calidad y socialmente integrada, aparece como un imposible en el imaginario de amplios sectores de la sociedad chilena actual.

\section{REFERENCIAS BIBLIOGRÁFICAS}

Alegre, M., \& Benito, R. (2012). 'The best school for my child?' Positions, dispositions and inequalities in school choice in the city of Barcelona. British Journal of Sociology of Education, 33(6), 849-871.

Alonso, L. (1996). Sujeto y Discurso. El lugar de la entrevista abierta en las prácticas de la sociología cualitativa. En J. Gutiérrez y J. Delgado (Coords.), Metodologías cualitativas de investigación social (pp. 225-240). Madrid: Síntesis.

Ball, S. (1993). Education markets, choice and social class : the market as a class strategy in the UK and the USA. British Educational Research Journal, 14(1), 3-19.

Ball, S. (2003). Class Strategies and the Education Market. London: Routledge.

Ball, S., Bowe, R., \& Gewirtz, S. (1996). School choice, social class and distinction: the realization of social advantage in education. Journal of Education Policy, 11(1), 89-112.

Ball, S., \& Reay, D. (1998). 'Making their Minds Up': family dynamics of school choice. British Educational Research Journal, 24(4), 431-448.

Bellei, C. (2009). The Private-Public School Controversy: The Case of Chile. In P. Peterson \& R. Chakrabarti (Eds.), School Choice International (pp. 165-192). Cambridge, MA: MIT Press.

Bellei, C. (2015). El gran experimento. Mercado y privatización de la educación chilena. Santiago: LOM Ediciones.

Bellei, C., González, P., \& Valenzuela, J. P. (2010). Fortalecer la educación pública, un desafío de interés nacional. En C. Bellei, J. P. Valenzuela \& D. Contreras (Eds.), Ecos de la Revolución Pingüina. Santiago: UNICEF - U. de Chile.

Bifulco, R., Ladd, H., \& Ross, S. (2008). Public school choice and integration evidence from Durham, North Carolina. Social Science Research, 38(1), 71-85.

Canales M. (2006). El grupo de discusión y el grupo Focal. En M. Canales (Coord., Ed.), Metodologías de Investigación Social. Introducción a los oficios (pp. 265-288). Santiago: LOM editores.

Canales, M. (2014). Investigación social. Lenguajes del diseño. Santiago: LOM Editores.

Canales, M., \& Peinado, A. (1995). El grupo de discusión. En J. Gutiérrez y J. Delgado, Métodos y Técnicas Cualitativas de Investigación Social (pp. 288-316). España: Editorial Síntesis.

Carrasco, A., \& San Martín, E. (2012). Voucher System and School Effectiveness: Reassessing School Performance Difference and Parental Choice Decision making. Estudios de Economía, 39(2), 123-141.

Castro, R., \& Kast, F. (2004). Movilidad de la pobreza en Chile. Análisis de la encuesta panel 1996/2001. Serie Informe Social N ${ }^{\circ}$ 85, Libertad y Desarrollo.

Chubb, J., \& Moe, T. (1990). Politics, markets, and America's schools. Washington, D.C.: Brookings Institution Press.

Contreras, D., Sepúlveda, P., \& Bustos, S. (2010). When Schools Are the Ones that Choose: The Effects of Screening in Chile. Social Science Quarterly, 91, 1349-1368.

Córdoba, C. (2014). La elección de escuela en sectores pobres: Resultados de un estudio cualitativo. Psicoperspectivas, 13(1), 56-67.

Da Costa, M., \& Koslinski, M. (2012). Escolha, estratégia e competição por escolas públicas. ProPosições, 23(2), 195-213.

Dauphin, N., \& Verhoeven, M. (2002). La mobilité scolaire au coeur des transformations du système scolaire. Cahier de recherche du GIRSEF, 19. Recuperado de https://halshs.archives-ouvertes.fr/ halshs-00603556/document 
Estudios Pedagógicos XLII, Nº 3: 89-109, 2016

¿POR QUÉ ELEGIR UNA ESCUELA PRIVADA SUBVENCIONADA? SECTORES MEDIOS EMERGENTES Y ELECCIÓN DE ESCUELA EN UN SISTEMA DE MERCADO

Duru-Bellat, M. (2004). Debates y prácticas en materia de elección de centros escolares en los países europeos y en los Estados Unidos. Revista de Educación, 333, 41-58.

Elacqua, G. (2012). The impact of school choice and public policy on segregation: Evidence from Chile. International Journal of Educational Development, 32(3), 444-453.

Elacqua, G., \& Fábrega, R. (2006). El consumidor de la educación: El actor olvidado de la libre elección de escuelas en Chile. En Educación y brechas de equidad en América Latina (pp. 353398). Santiago: PREAL.

Espínola, V. (1993). The educational reform of the military regime in Chile: The school system's response to competition, choice and market relations (Tesis de Doctorado). University of Wales, UK.

Espinoza, V., Barozet, E., \& Méndez, M. L. (2013). Estratificación y movilidad social bajo un modelo neoliberal: El caso de Chile. Revista Lavboratorio, 14(25).

Friedman, M. (1955). The Role of Government in Education. In R. A. Solo (Ed.), Economics and the Public Interest (pp. 85-107). New Brunswick, N.J.: Rutgers University Press.

Gallego, F., \& Hernando, A. (2009). School choice in Chile: looking at the demand side. Documento de trabajo $N^{\circ}$ 356. Santiago: Instituto de Economía PUC.

Haynes, K. T., Phillips, K. J. R., \& Goldring, E. B. (2010). Latino Parents' Choice of Magnet School: How School Choice Differs Across Racial and Ethnic Boundaries. Education and Urban Society, 42(6), 758-789.

Hsieh, C.T., \& Urquiola, M. (2003). When schools compete, how do they compete? An assesment of Chile's nationwide school voucher program. NBER Working Paper 10008. Cambridge, MA: National Bureau of Economic Research.

Ibáñez, J. (1979). Más allá de la sociología. El grupo de discusión, teoría y práctica. Madrid: Siglo XXI.

Lauen, L. L. (2007). Contextual Explanations of School Choice. Sociology of Education, 80(3), 179209.

León, A., \& Martínez, J. (1998). La estratificación social chilena hacia fines del siglo XX. En C. Toloza y E. Lahera (Eds.), Chile en los noventa (pp. 285-311). Santiago: Presidencia de la República y Dolmen Ediciones.

Levin, H., \& Belfield, C.R. (2006). The marketplace in education. In H. Lauder, P. Brown, J. Dillabough, \& A.H. Halsey (Eds.), Education, Globalization \& Social Change (pp. 620-641). Oxford: Oxford University Press.

Mena, P., \& Corbalán, F. (2010). La selección escolar: una cuestión de libertad, competencia, igualdad e integración. En C. Bellei, J. P. Valenzuela y D. Contreras (Eds.), Ecos de la Revolución Pingüina (pp. 331-363). Santiago: UNICEF - Universidad de Chile.

Mizala, A., \& Torche, F. (2012). Bringing the schools back in: the stratification of educational achievement in the Chilean voucher system. International Journal of Educational Development, $32(1), 132-144$.

Navarro, L. N. (2004). La escuela y las condiciones sociales para aprender y enseñar. Buenos Aires: UNESCO \& IIPE.

OCDE. (2010). Perspectivas Económicas de América Latina 2011: En qué medida es clase media América Latina. París: OECD Publishing.

Olmedo, A., \& Santa Cruz, E. (2007). El proceso de valoración de los centros educativos por parte de las familias de clase media. El papel del orden expresivo en la búsqueda de distinción. Papers: Revista de Sociología, 96(2), 515-537.

Pérez-Díaz, V., Rodríguez, J., \& Sánchez Ferrer, L. (2001). La familia española ante la educación de sus hijos. Barcelona: Fundación La Caixa.

PNUD. (1998). Las paradojas de la modernización. Desarrollo humano en Chile 1998. Santiago: Programa de las Naciones Unidas para el Desarrollo.

PNUD. (2002). Nosotros los chilenos: un desafio cultural. Desarrollo Humano en Chile 2002. 
Santiago: Programa de las Naciones Unidas para el Desarrollo.

Raczynski, D., \& Hernández, M. (2011). Elección de colegio, imágenes, valoraciones y conductas de las familias y segregación social escolar. Santiago: Asesorías para el desarrollo.

Rambla, X. (2003). Las desigualdades de clase en la elección de escuela. Revista de Educación, 330, 83-98.

Raveaud, M., \& van Zanten, A. (2007). Choosing the local school: middle class parents' values and social and ethnic mix in London and Paris. Journal of Education Policy, 22(1), 107-124.

Ruiz-Encina, C., \& Orellana, V. (2011). Panorama social de Chile en el bicentenario. Revista Análisis del Año 2010 (pp. 27-52). Departamento de Sociología, Facultad de Ciencias Sociales. Santiago: Universidad de Chile.

Saavedra, C. (2013). Efecto del Financiamiento Compartido sobre el Rendimiento Escolar. (Tesis para optar al grado de Magíster de Economía Aplicada, Escuela de Ingeniería). Universidad de Chile, Santiago.

Taylor, S. J., \& Bogdan, R. (1987). Introducción a los métodos cualitativos de investigación. La búsqueda de significados. Buenos Aires: Paidós.

Torche, F., \& Wormald, G. (2004). Estratificación y movilidad social en Chile: entre la adscripción y el logro. Serie Políticas Sociales de la CEPAL, No 85, CEPAL.

Valenzuela, J. P., Bellei, C., \& Ríos, D. D. L. (2014). Socioeconomic school segregation in a marketoriented educational system. The case of Chile. Journal of Education Policy, 29(2), 217-241.

Valles, M. (2015). La entrevista cualitativa. Madrid: CIS, Centro de Investigaciones Sociológicas.

Van Zanten, A. (2003). Middle-class Parents and Social Mix in French Urban Schools : reproduction and transformation of class relations in education. International Studies in Sociology of Education, 13(2), 107-124.

Van Zanten, A. (2007). Reflexividad y elección de la escuela por los padres de la clase media en Francia. Revista de Antropología Social, 16, 245-277.

Veleda, C. (2007). Entre querer y poder: Las clases medias y la elección de la escuela en el conurbano bonaerense. En M. Narodowski y M. Gómez Schettini, (Comps.), Escuela y Familias: Problemas de diversidad cultural y justicia social (pp. 127-172). Buenos Aires: Prometeo.

Witte, J. F. (2009). Vouchers. In G. Sykes, B. Schneider \& D. Plank (Eds.), Handbook of Education Policy Research (pp. 491-501). New York, NY: American Educational Research Association, Routledge.

Yoon, E., \& Gulson, K. (2010). School choice in the stratilingual city of Vancouver. British Journal of Sociology of Education, 31(6), 703-718. 
